\title{
Transformational Leadership and Performance of Deposit-Taking Saccos in Nairobi City County: Kenyan Perspective
}

\author{
Catherine Njoki Prof. Peter. O. K'Obonyo, PhD Dr. Florence Muindi, PhD. \\ School of Business, University of Nairobi \\ P. O. Box 30197-00100 Nairobi, Kenya
}

\begin{abstract}
Organizational leaders are crucial in motivating and helping their employees to be competitive and committed to the achievement of organizational goals and objectives by use of effective leadership styles. Transformational leadership influences the fundamental attitudes and assumptions of an organization's members, creating a common mentality to attain the organization's goals and this leadership style usually generates higher performance. The major objective of this study was to establish the relationship between transformational leadership and performance of Deposit taking SACCOs in Nairobi City County, Kenya. The theories chosen to anchor the variables in this study was transformational leadership theory. This study adopted descriptive cross-sectional research design. The population of the study was the (40) deposit taking savings and cooperative societies in Nairobi City County as at December 2016. The researcher collected data from the forty chief executive officers of the SACCOs and randomly selected ten employees from each SACCO. This gave four hundred and forty (440) respondents who are far much more than the recommended three hundred and eighty four (384) respondents. The data for the study was both primary and secondary quantitative data. Multiple regression models were used to test the significance of the influence of the independent variable on the dependent variable. T-test was used to test the direction of the relationship between the dependent and the independent variable. The results of the study findings were established and compared to various theories anchoring the study and conceptual, contextual and empirical evidence. The study found a relatively strong relationship between transformational leadership and financial performance as well as non-financial measures. It was also established that transformational leadership have a positive and statistically moderate relationship with employee commitment.
\end{abstract}

Keywords: Transformational leadership, SACCOs, Performance, Nairobi City County

DOI: $10.7176 / \mathrm{EJBM} / 14-2-05$

Publication date: January $31^{\text {st }} 2022$

\section{INTRODUCTION}

In any organization, leaders are crucial in motivating and helping their employees to be competitive and committed to the achievement of organizational goals and objectives by use of effective leadership styles (Enayat, 2013). Transformational leadership influences the fundamental attitudes and assumptions of an organization's members, creating a common mentality to attain the organization's goals and this leadership style usually generates higher performance. Although evidence shows that transformational leaders exercise a substantial influence on performance, understanding of the processes through which they exert this influence is still limited and largely speculative. Erkutla (2000) says that there are few studies that trace the causal path of the effects of transformational leadership on performance systematically by examining the intermediate influence of the transformational leaders' perceptions of different variables related to performance. Organizational performance is recognized as being critical to an organization's growth and continued existence in the active business environment (Raluca-Elena, 2015). The concept of organizational performance is critical since it has inspired significant interest among scholars and researchers, especially on how return on investment can be attained. Raluca-Elena (2015) suggests that transformational leadership practices have a positive influence on organizational performance.

With the future being predicted in terms of technological, social, competitive and legal scenarios, good leadership is regarded as the key to maintain and retain employees and ensure successful change management in today's firms. Transformational leaders are associated with the ability to show how beneficial practice development is through inspiring a change of culture, positive team work, being adaptable and goal oriented (Yukl, 2010). The present examination is expected to add to literature, for there is lack of exact confirmation about how transformational leadership influences organizational performance at the organization's level (Jung, 2003). Even though research on contemporary leadership focuses more on transformational leadership and positive effects have earned good reputation, little is known of how its effectiveness is influenced by context (Yukl, 2010). On the other hand, the significance of transformational leadership on firms has created a big debate and researchers are arguing that the environment which includes culture and employees among others, make transformational leadership difficult to pursue (Currie and Lockett, 2007). This study was anchored on transformational leadership theory. Transformational leadership theory contends that a transformational leader identifies the needs of the supporters with high motivation and maturity (Burns, 1978).

The Deposit Taking Savings and Credit Cooperative societies (DTSACCOs) in Kenya are said to be the 
largest in Africa (SASRA, 2012). They contribute significantly to the country's domestic savings, forming a vital component of Kenya's economic and social development. At least one out of every five Kenyans depends on DTSACCOs for their livelihood and social wellbeing (SASRA, 2012). The DTSACCOs are players in the financial industry among others. The financial industry is a dynamic industry with a relatively modest history in Kenya and requires visionary leaders. In the financial industry, customer is the king and every act of the employee is driven by the service demand of customers. Among the different sorts of advancements, leadership is an essential path for the DTSACCOs to accomplish upper hand and in this way improve performance. Transformational leadership has been established as the most effective way in which leaders influence in firms can be seen (Horner, 2007). Nevertheless, when compared to the other parts of the world, few studies have been conducted in developing countries, to be specific, Kenya.

\section{STATEMENT OF THE PROBLEM}

Explaining why firms in the same industry and markets differ in their performance remains a fundamental question within management circles (Walker, 2007). There is no single explanation on the source of variation in performance but can partly be explained by a number of factors, key among them: leadership (Bourgeois, 2003). Leadership and performance are facets that are dealt with concurrently in an attempt to explain why organizations in similar industries and markets contrast in their performance. Performance of SACCOs is important to the Kenyan economy as deposit taking SACCOs is among the sectors which will spur economic development and help the country realize vision 2030. An empirical research proposed by this study will help shed light on causes of variation in performance of deposit taking SACCOs in Nairobi City County in a bid to fill this conceptual gap.

The DTSACCOs in Kenya are facing challenges emanating from factors such as globalization, competition and technological changes which mean that the sector requires innovative ways to survive (SASRA, 2013). The leadership of DTSACCOs in Kenya is based on a democratic manner where members elect a board of management which in turn is responsible of determining the managers who run the day-today activities of the DTSACCOs. Most of these leaders who take up the positions have low managerial qualifications and experience hence difficult to have leaders with transformational leadership characteristics (Njoroge, 2008).

The DTSACCOs are characterised by a culture of nepotism which is manifest in the employment procedures and hence most employees have low qualifications and expertise which makes them less committed to deliver the services effectively (Nyambere, 2013). DTSACCOs in Kenya have also been found to retire their employees early in order to evade the salaries they should be paid following their experience and expertise (Karanja, 2013). Many qualified leaders leave management and leadership to the young inexperienced persons which make the DTSACCOs to be viewed as organizations which operate locally and characterized by inefficiency (Mirrie, 2014). The Kenyan DTSACCOs sector has been known to be conservative to these traditional undertakings and this study follows the curiosity to fill this contextual gap.

Some of the empirical studies done on performance of SACCOs have brought forth diverse results. Studies on SACCOs in Kenya, such as: Kilonzi (2012) assessed the impact of SASRA regulations on financial performance and found that the performance of DTSACCOs improved with post SASRA regulations; Karanja (2013) assessed the relationship between size and performance and found that less efficient DTSACCOs had less ROE; Nyambere (2013) examined the impact of credit risk management on financial performance found that ROE is an improper measure of financial performance; Mwangi (2014) investigated the relationship of individuals' salary and conduct of SACCOs in the association between features and usefulness of SACCOs and found that conduct of SACCOs was not a significant intervening variable between characteristics and efficiency. These studies conducted in Kenya on performance of SACCOs have focused on the firm's specific factors and others on balanced scorecard as a tool to improve performance.

Globally, a study by Achmad \& Vivin (2012) on the effect of transformational leadership and employee commitment on work performance in state funded colleges, found out that transformational leadership affects work performance while employee commitment has an indirect impact. A study by Walker (2007) on how firms can increase their market share and profitability suggests that employee characteristics highly determine the leadership efforts and those situational contexts that influence the rate of organizational adaptation to change. A study by Slade (2009) on the role of transformational leaders in facilitating culture change in health organizations found that transformational leaders played a positive role in enhancing culture change which increased performance. These studies may not apply to firms in the Kenyan context, hence the need for an empirical investigation in a Kenyan context to bridge the contextual knowledge gap. None of these studies has focused on the influence of transformational leadership on organizational performance. This study takes cognizance of the fact that performance of DTSACCOs may be a function of factors key among them leadership.

Kilonzi (2012) carried out a study on impact of SASRA regulations on financial performance of SACCOs using causal research design and purposive sampling. Langat (2012) used crossectional survey in his study on factors influencing performance of SACCOs in Bomet County. Similarly Ping Zhou et al., (2009) used survey method to study perceptions of organizational culture among employees. A study by Jirapa (2015) on determinants 
of profitability of MFIs in Africa used quantitative research design to assess the profitability. He observed that there was a positive relationship between size and profitability of MFIs. From literature it shows that several researchers have studied performance of organizations using varied methods and yielding varied results. The study will seek to find out if similar results will be got by using descriptive cross sectional design and simple random sampling method to select the respondents. To address the above mentioned gaps, namely; contextual, conceptual, knowledge and methodological gaps, this study will answer the question: what is the relationship between transformational leadership and organizational performance of Deposit Taking Saving and Credit Cooperative Societies in Nairobi City County, Kenya.

\section{OBJECTIVE OF THE STUDY}

The main objective of this study was to establish the the effect of transformational leadership on performance of Deposit-Taking SACCOs in Nairobi City County, Kenya.

\section{LITERATURE REVIEW}

\section{Theoretical Foundation of the study}

This section reviews the various theories on which this study is anchored. The study will be anchored on transformational leadership. The theory will provide an important understanding of human behaviours and factors that help channel such behaviours leading to organizational performance

\section{Transformational Leadership Theory}

Transformational leadership theory refers to behaviours in the context of rational exchanges between leaders and followers, typically with a view to the accomplishment of a prescribed task or goal. The theory states that authority bestowed to leaders is depended on them being able to have unique qualities which make them to stand out (Bennet, 2009). However, the transformational leadership concept by Burns (1978) suggests that leadership can occur in two forms; transactional and transformational. Bass (1985) version of transformational leadership is different from Burns' theory; that transformational and transactional are not different from each other but are just from different scopes and that transformational leadership accounted for unique variance in performance (Bass \& Riggio 2006).

Transformational leadership theory describes the way the leaders encourage and support their followers in achieving set goals by clarifying the path for their followers to know the way, by removing any roadblocks that hinder performance and final by increasing their rewards when goals are achieved. According to Bass (2006), the theory shows the extent to which a leader influences followers as followers go for leaders because of trust and honesty which increases the followers' loyalty towards the leader.

Transformational leadership theory highlights a dimension whereby the leader: is a model of respectability and fairness, characterizes clear goals, has raised standards, stimulates others, offers assistance and affirmation, mixes the sentiments of people, propels people to look past their self-interests and moves people to pursue the doubtful (Bass 2005). As indicated by Bass and Riggio (2006) transformational leadership motivates supporters by speaking to their high needs and encourage employees to go beyond self-enthusiasm for the sake of the organization. However, transactional leadership bids to the supporters' lower-level individual needs in light of instrumental monetary exchanges (Bennet, 2009).

Transformational leadership is not devoid of criticism. Northhouse (2007) says that transformational leadership is anti-democratic and emphasizes heroic features of leadership. They create and converse the vision to bring change. This may be seen as if they are acting independent of their supporters. Nevertheless, Bass and Riggio (2006) do not support this type of criticism and claim that transformational leaders are not anti-democratic but have a soothing and compelling approach to their followers. Secondly transformational leadership can be misused when leaders change staff values and give them a new vision for the future (Riggio, 2006). This study therefore seeks to operate within the framework of transformational leadership theory.

\section{Empirical Literature Review}

Various researchers around the world have looked at the influence of transformational leadership on organizational performance. In Canada, Hancott (2014) established that the best performing companies were significantly using transformational leadership as compared to poor performing companies. The argument is supported by Mortazavi and Partovi (2014) findings that transformational leadership has a positive and significant influence on organizational commitment, employee motivation and job satisfaction in Iran. Veiseh et al., (2015) also found that the characteristics of transformational leadership such as inspirational motivation, idealized influence, individual consideration and intellectual stimulation influence both organizational culture and performance. In Turkey, Erkutlu (2008) indicates that transformational leadership stimulates organizational commitment which in turn influences job satisfaction and hence organizational performance.

According to Bass and Avolio (2002), transformational leadership is the act of integrating four aspects: idealized influence, inspirational motivation, intellectual stimulation and individualized consideration. Idealized 
influence refers to the ability of building confidence in the leader and appreciation of the leader by his followers, which forms the basis for accepting radical change in the organization. Without such confidence in the leader, that is, in his motives and aims, an attempt to redirect the organization may cause great resistance (Chong \& Wolf, 2010). Inspirational Motivation reflects the extent to which a leader is capable of being a cheer leader and able to speak on behalf of his followers (Jung \& Avolio, 2000). A leader with high inspirational motivation demonstrates enthusiasm, optimism, emphasize commitment as a shared goal and act as a figure that inspires and motivates the followers to appropriate behaviour and teamwork (Enayat, 2013). Transformational leaders reflect their awareness of teamwork and readiness to learn on the help of others. The leader creates functioning teams to a level which insures complete equality (Northouse, 2007).

Intellectual Stimulation is an aspect that allows transformational leaders to be able to stimulate the efforts of their followers as regards innovativeness, creativity and re-examination of the existing assumptions (Enayat, 2013). This makes it possible for employees to get creative ideas for solving problems and instils creativity as well as encouraging flowers to approach problems in new ways (Northouse, 2007). By appreciating the creative efforts of the followers, a strong motivational basis from their active involvement in the process of change is achieved. Individualized consideration refers to the ability to do individual analysis of followers by inclusion of followers into the transformational process of an organization (Ogbonna and Harris, 2000). This helps transformational leader to diagnose the followers' wishes, needs, values and abilities in the right way. By acting in this manner transformational leaders are able to create a two way communication of responsibility and recognition (Northouse, 2007). The present study expounds on how transformational leadership impacts organizational performance regarding these four components.

In Egypt, ElKordy (2013) established that transformational leadership is significantly used in both public and private institutions. In addition, individualized consideration, Intellectual stimulation and inspirational motivation were found to improve organizational performance.. These findings are supported by Abasilim (2014) argument that transformational leadership style has a positive and significant influence on organizational performance in Nigeria. Even though several studies show that several organizations are adopting transformational leadership, there is little empirical evidence on the role of transformational leaders on organizational performance in the deposit taking Saccos in Kenya. Based on the above discussion, the current study will propose that idealized influence, inspirational motivation, intellectual stimulation and personalized consideration, which represent the main characteristics of transformational leadership, will have a positive effect on organizational performance.

\section{RESEARCH METHODOLOGY}

This study adopted descriptive cross-sectional research design as data was collected from a cross-section of the organizations at one point in time. This is in line with Mugenda and Mugenda (2003), who posits that, the design allows the use of regression in order to sort out the existence and magnitude of causal effects of one or more independent variables upon a dependent variable of interest at a given point in time.

The population for this study was the (40) deposit taking savings and cooperative societies in Nairobi City County as at December 2016. The researcher reached out to the CEOs and employees of the 40 deposit taking savings and cooperative societies which constitute a population greater than thousand $(10,000)$ elements. According to Mugenda and Mugenda (2003), a population is considered large if it has more than ten thousand members, hence three hundred and eighty four (384) respondents from such a large population is sufficient for the study. The researcher was to collect data from the forty chief executive officers of the SACCOs and randomly select ten employees from each SACCO. This gave four hundred and forty (440) respondents who are far much more than the recommended three hundred and eighty four (384) respondents.

The data for the study was both primary and secondary quantitative. Primary data was collected on transformational leadership and performance. The data collected on organizational performance was both financial and non-financial. Financial data was collected about the SACCO's return on investment and operating margin, while non-financial data was collected on SACCO's customer satisfaction and quality of services. Secondary data was obtained from annual reports of SACCOs and reports from the SACCO Societies Regulatory Authority. Primary data was gathered using structured questionnaires with statements anchored on a likert-type five point scale. Likert scale is useful in measuring perceptions, attitude, values, and behaviour and assists to convert the qualitative responses into quantitative values (Zikmund, 2010).

Qualitative data was measured using likert scale and content analysis will be carried out to understand the relationship of the independent variable with the dependent variable. Principal component analysis was conducted to determine the significant factors in the financial performance of deposit taking SACCOs. High values ranging between 0.4 and 1.0 indicated that the factor is appropriate while a value below 0.4 will mean that the factor is not appropriate (Mugenda \& Mugenda, 2008). This provided the basis for removal of the redundant variables in the proposed model.

In order to determine the accuracy level of the independent variable in predicting the dependent variable Cox and Snell's R-squared was used and Nagelkerkel's R-squared was used to test the strength of the overall 
relationship of the independent variable in predicting the dependent variable (Gujarat, 2009). T-test was used to test the direction of the relationship between the dependent and the independent variable. A negative value indicated that as one variable increases the other variable decreases, while a positive value mean that if one variable increases the other variable also increases.

Multiple regression models were used to test the significance of the influence of the independent variable on the dependent variable. Machuki (2011) used regression analysis in his study on the empirical analysis of interest rate spread in Kenya. Fischer distribution test (F-test) was used to test the significance of the independent variable and the overall model. The p-value for the F-statistic was used to determine the robustness of the model. It was used to accept or reject the null hypothesis. If P-value is greater than 0.05 the null hypothesis is accepted then the overall model was insignificant and if P-value is less than 0.05 the null hypothesis is rejected then the overall model was significant and has good predictors and the results are not based on chance.

\section{RESEARCH FINDINGS AND DISCUSSIONS}

This subsection presents the results of the tests for the hypothesis of the study which was formulated from the main research objective. The objective sought to establish the effect of transformational leadership on performance of Deposit-Taking SACCOs in Nairobi City County, Kenya. Transformational leadership and non-financial performance required employees and CEOs' respondents to rate the extent to which given statements matched their perception in the specified areas using a Likert type scale of 1 to 5, with 1 representing 'not at all'/ 'strongly disagree' and 5representing 'to a very large extent'/ 'strongly agree'.

The overall regression analysis to test for the first hypothesis of this study was thus based on the combined perceptions of employees and CEOs'. Also, the CEOs' respondents were asked to give the financial performance of their organizations in terms of their organization's operating margin and return on investment. This objective was tested for through two sub-hypotheses.

H1a: Transformational leadership has a statistically significant effect on financial organizational performance; and H1b: Transformational leadership has a statistically significant effect on organizational non-financial performance.

Transformational leadership and financial performance

The study determined the effect of transformational leadership on financial performance. This was done by getting the composite index of Transformational leadership and financial performance constructs by using simple linear regression analysis. The results are depicted in Table 1.

Table 1: Regression Results for the Effect of Transformational Leadership on Financial Performance Model Summary

\begin{tabular}{|l|r|r|r|r|}
\hline Model & R & \multicolumn{1}{|c|}{ R Square } & \multicolumn{1}{c|}{ Adjusted R Square } & Std. Error of the Estimate \\
\hline 1 & $.459^{\mathrm{a}}$ & .211 & .209 & .53950 \\
\hline
\end{tabular}

a. Predictors: (Constant), Transformational Leadership

ANOVA $^{\mathrm{a}}$

\begin{tabular}{|ll|r|r|r|r|r|}
\hline Model & & Sum of Squares & df & Mean Square & F & Sig. \\
\hline 1 & Regression & 25.687 & 1 & 25.687 & 88.256 & $.000^{\mathrm{b}}$ \\
& Residual & 96.049 & 330 & .291 & & \\
& Total & 121.737 & 331 & & & \\
\hline
\end{tabular}

a. Dependent Variable: Financial performance

b. Predictors: (Constant), Transformational Leadership

Coefficients $^{\mathrm{a}}$

\begin{tabular}{|c|c|c|c|c|c|c|}
\hline \multirow{2}{*}{\multicolumn{2}{|c|}{ Model }} & \multicolumn{2}{|c|}{ Unstandardized Coefficients } & $\begin{array}{l}\text { Standardized } \\
\text { Coefficients }\end{array}$ & \multirow[b]{2}{*}{$\mathrm{t}$} & \multirow[b]{2}{*}{ Sig. } \\
\hline & & $\mathrm{B}$ & Std. Error & Beta & & \\
\hline 1 & (Constant) & 1.910 & .146 & & 13.092 & .000 \\
\hline & $\begin{array}{l}\text { Transformational } \\
\text { Leadership }\end{array}$ & .432 & .046 & .459 & 9.394 & .000 \\
\hline
\end{tabular}

a. Dependent Variable: Financial performance

The study found a relatively moderate relationship between transformational leadership and financial performance $(\mathrm{R}=.459)$. Coefficient of determination $\left(\mathrm{R}^{2}=.211\right)$ indicates that Transformational leadership explains $21.1 \%$ of variation in financial performance. The relationship is significant $(\mathrm{F}=88.256, \mathrm{p}<0.05)$. The significant relationship is further revealed by the $t$-value in the coefficient table $(\beta=.432, t=9.394, p<0.05)$. This therefore indicates that transformational leadership is key in determining financial performance in Deposit-Taking SACCOs in Nairobi City County, Kenya and thus the hypothesis that Transformational leadership will be 
positively associated with financial performance was confirmed.

Based on the outcomes of the results of the regression analysis as presented in Table 1, the model is substituted as follows:

$\mathrm{Y}=1.910+.432 \mathrm{X}_{1}$

Where $\mathrm{Y}$ is financial performance and $\mathrm{X}_{1}$ is transformational leadership. This implies that a unit change in transformational leadership results in .432 changes in financial performance of Deposit-Taking SACCOs in Nairobi City County, Kenya. However, when transformational leadership is held constant, financial performance is 1.910. This implies that transformational leadership significantly adds to financial performance of DepositTaking SACCOs in Nairobi City County, Kenya.

\section{Transformational leadership and non-financial performance}

The study determined the effect of transformational leadership on non-financial performance. This was done by getting the composite index of Transformational leadership and non-financial performance constructs by using simple linear regression analysis. The results 2

Table 2: Regression Results for the Effect of Transformational Leadership on Non-Financial Performance Model Summary

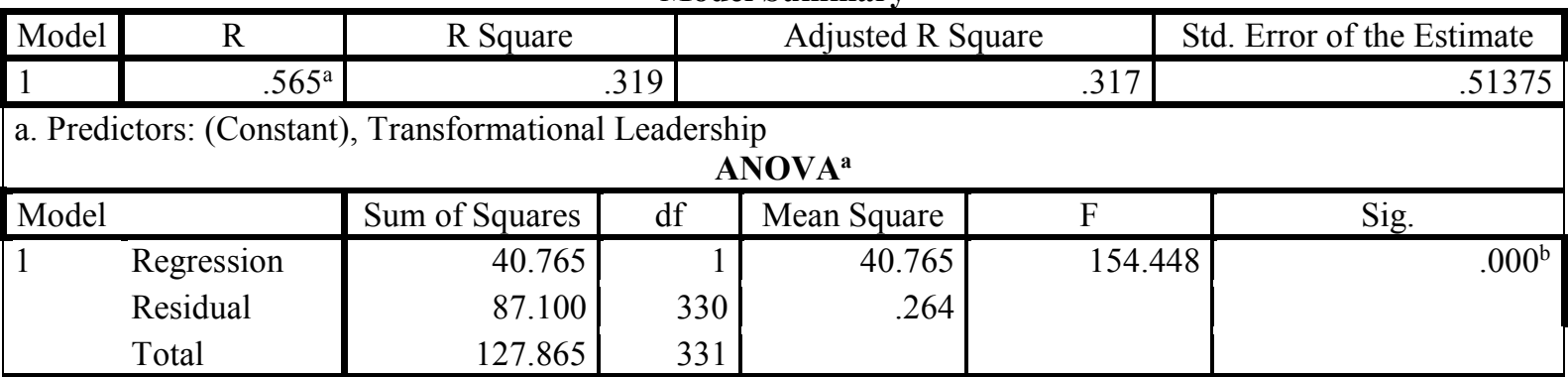

a. Dependent Variable: Non-financial performance

b. Predictors: (Constant), Transformational Leadership Coefficients $^{\mathbf{a}}$

\begin{tabular}{|c|c|c|c|c|c|c|}
\hline \multirow{2}{*}{\multicolumn{2}{|c|}{ Model }} & \multicolumn{2}{|c|}{$\begin{array}{c}\text { Unstandardized } \\
\text { Coefficients }\end{array}$} & \multirow{2}{*}{$\begin{array}{c}\text { Standardized } \\
\text { Coefficients }\end{array}$} & \multirow[b]{2}{*}{$\mathrm{t}$} & \multirow[b]{2}{*}{ Sig. } \\
\hline & & $\mathrm{B}$ & Std. Error & & & \\
\hline 1 & (Constant) & 1.551 & .139 & & 11.169 & .000 \\
\hline & $\begin{array}{l}\text { Transformational } \\
\text { Leadership }\end{array}$ & .544 & .044 & .565 & 12.428 & .000 \\
\hline
\end{tabular}

a. Dependent Variable: Non-financial performance

Table 2 shows a strong correlation between transformational leadership and non-financial performance $(\mathrm{R}=.565)$. Coefficient of determination $\left(\mathrm{R}^{2}\right)=.319$, suggesting that transformational leadership explains $31.9 \%$ of variation in non-financial performance. Also, it is noted from the results that the regression model achieved goodness of fit level of $(\mathrm{F}=154.448, \mathrm{p}<0.05)$.

The significant relationship is further manifested by the $\mathrm{t}$-value in the coefficients table $(\beta=.544 \mathrm{t}=12.428$, $\mathrm{p}<0.05)$. This implies that the influence transformational leadership is key in determining non-financial performance of employees in Deposit-Taking SACCOs in Nairobi City County, Kenya and thus the hypothesis that Transformational leadership is positively associated with SACCOs non-financial performance is confirmed. Based on the results of the regression analysis in Table 4.24, the model is substituted as follows:

$\mathrm{Y}=1.551+.544 \mathrm{X}_{1}$

Where $\mathrm{Y}$ is non-financial performance and $\mathrm{X}_{1}$ is transformational leadership. This implies that a unit change in transformational leadership results in .544 change in non-financial performance of Deposit-Taking SACCOs in Nairobi City County, Kenya. Further, when transformational leadership is held constant, non-financial performance is 1.551 units as shown by a constant value $(\beta o)$. This implies that transformational leadership significantly adds to non-financial performance of Deposit-Taking SACCOs in Nairobi City County, Kenya.

\section{CONCLUSION AND RECOMMENDATION}

This finding concurs with Transformational leadership theory that depicts characteristics of transformational leadership such as inspirational motivation, idealized influence, individual consideration and intellectual stimulation to influence performance. The study established that there is a significant influence of transformational leadership on financial organizational performance and non-financial performance. The findings suggested that SACCO leadership played a huge role towards the success of the organizations. That is, transformational leaders play a role in making it possible for employees to get creative ideas for solving problems and instill creativity as 
well as encouraging followers to approach problems in new ways. Additionally, they represented role modeling behaviour where the leaders instilled pride, faith, and respect, as well as portrayed very high moral standard and ethical conduct and could be relied on to provide followers with a vision and sense of mission. These specific, possibly unique individual strengths are then complimented by the strengths of others, or of the team as a unit. Additionally, working as a team involves active discussion, giving room for brainstorming and open communication. Communication can initiate diverse approaches and thoughts that can support decision making hence bring about to better performance of the SACCO.

\section{REFERENCES}

Abasilim, U.D.(2014). Transformational leadership style and its relationship with organizational performance in Nigeria work context. IOSR Journal of Business and Management, 16(9), 01-05.

Achmad Sani and Vivin Maharani (2012). The impact of transformational leadership and organizational commitment on job performance. International Journal of Academy research part B; 2012; 4(4).

Bass, B. M., \& Riggio, R. E. (2006). Transformational Leadership. Mahwah, NJ: Lawrence Erlbaum.

Bass, B.M. (1985). Leadership and Performance beyond expectations, (Free press, New York

Bass, B.M. (2005). Leadership: Good, better, best. Organizational Dynamics. 13 (3): 26-40

Bass, B.M. and Avolio, B.J. (2002); Developing transformational leadership; industrial training 14(5), 21-27.

Bennett, T. M. (2009). A study of the management leadership style preferred by IT subordinates.

Burns, J. M. (1978). "Leadership. New York, NY: Harper \& Row

Burns, J. M. (1978). "Leadership. New York, NY: Harper \& Row.

Chong, E. and Wolf, H. (2010) Factors Influencing Followers' Perception of Organisational Leaders, Leadership \& Organization Development Journal, 31, pp. 402-19.

ElKordy, M. (2013). Transformational leadership and organizational culture as predictors of employees attitudinal outcomes. Business management dynamics, 3(5),15-26

Enayat, A. (2013). The role of transformational leadership and organizational culture in improving performance of Iranian Agricultural facilities to become leading organizations. Department of Agricultural extension and education, Tarbiat Modares University, Tehran

Erkutla, H. (2008). The impact of transformational leadership on organizational and leadership effectiveness. the Turkish case, journal management development, 27(7), 708-726.

Erkutla, H. (2008). The impact of transformational leadership on organizational and leadership effectiveness. the Turkish case, journal management development, 27(7), 708-726.

Jung, D., and Avolio, B. (2000), Opening the Black Box: An Experimental Investigation of the Mediating Effects of Trust and Value Congruence on Transformational and Transactional Leadership, Journal of Organizational Behaviour, 21, 949-964.

Karanja, J. N.( 2013). The relationship between size and cost efficiency of SACCOs with front office services activity in Kenya. Unpublished MSc Finance Project, University of Nairobi.

Kilonzi.B.K. K. (2012). "The impact of SASRA regulations on the financial performance of SACCOs in Kenya". Unpublished MBA project, University of Nairobi.

Machuki V. N.,\& Aosa, E.(2011). The influence of the external environment on the performance of publicly quoted companies in Kenya. Prime Journal of Business Administration and Management, 1(7) 205218.

Mortazavi, N. \& Partovi, N. (2014). Analysis of the effect of transformational leadership on organizational performance with human resource approach (case study: Keshavarzi Bank), MAGNT Research Report, 2(1), 277-285.

Mugenda, O.M., \& Mugenda, A .G. (2008). Research Methods, qualitative and quantitative approaches. Nairobi: Acts Press.

Mwangi .M. (2014). The influence of members' income and conduct of SACCOs in the relationship between characteristics and efficiency of SACCOs in Kenya. Unpublished PhD thesis, University of Nairobi.

Njoroge,L.W.N. (2008): Determinants of financial performance in Savings and credit cooperative societies in Nairobi. Unpublished MBA project, University of Nairobi.

Northouse, P.G. (2007). Leadership, Theory and Practice, fourth edition, Thousand Oaks, CA: Sage Publications.

Nyambere, F.K. (2013). Effect of credit risk management on financial performance in Savings and Credit Cooperative Societies in Kenya, Unpublished MBA Project, university of Nairobi

Nyambere, F.K. (2013). Effect of credit risk management on financial performance in Savings and Credit Cooperative Societies in Kenya, Unpublished MBA Project, university of Nairobi.

Raluca-Elena, H. (2015). The impact of leadership on organizational performance. SEA- Practical application of Science, 3(1), 7-15.

SASA, (2011), Sacco Supervision Report 2011 (Deposit Taking Saccos). Nairobi: SASRA

Slade, N. (2009). Personal recovery and mental illness. A guide for mental health professionals. Cambridge, MA: Cambridge University Press. 
Veiseh, S.,Mohammadi, E., Pirzadian, M, \& Sharafi, V. (2015). The relation between transformational leadership and organizational Culture (Case study: Medical school of Ilam). Journal of business studies Quarterly, 5(3), $113-121$

Walker. H.F (2007). Factors influencing organizational change efforts. An integrative investigation of change, context, process and individual differences. Journal of organizational change management. Vol 20 no.6.

Zikmund, W.G. (2010). Business Research Methods ( $7^{\text {th }}$ ed). Thompson publishers: New York. 